Review

\title{
Biology and Function of miR159 in Plants
}

\author{
Anthony A. Millar*, Allan Lohe and Gigi Wong \\ Division of Plant Science, Research School of Biology, The Australian National University, \\ Canberra ACT 2601, Australia \\ * Correspondence: tony.millar@anu.edu.au
}

Received: 10 May 2019; Accepted: 23 July 2019; Published: 30 July 2019

\begin{abstract}
MicroR159 (miR159) is ancient, being present in the majority of land plants where it targets a class of regulatory genes called GAMYB or GAMYB-like via highly conserved miR159-binding sites. These GAMYB genes encode R2R3 MYB domain transcription factors that transduce the gibberellin (GA) signal in the seed aleurone and the anther tapetum. Here, GAMYB plays a conserved role in promoting the programmed cell death of these tissues, where miR159 function appears weak. By contrast, GAMYB is not involved in GA-signaling in vegetative tissues, but rather its expression is deleterious, leading to the inhibition of growth and development. Here, the major function of miR159 is to mediate strong silencing of GAMYB to enable normal growth. Highlighting this requirement of strong silencing are conserved RNA secondary structures associated with the miR159-binding site in GAMYB mRNA that promotes miR159-mediated repression. Although the miR159-GAMYB pathway in vegetative tissues has been implicated in a number of different functions, presently no conserved role for this pathway has emerged. We will review the current knowledge of the different proposed functions of miR159, and how this ancient pathway has been used as a model to help form our understanding of miRNA biology in plants.
\end{abstract}

Keywords: miR159; GAMYB; programmed cell death; aleurone; tapetum; vegetative growth; flowering

\section{Introduction}

Associated with the emergence and diversification of land plants, is a core set of conserved microRNA (miRNA) families that arose early in terrestrial plant evolution and which are conserved in modern day plant species [1]. This conservation implies these endogenous gene regulators are fundamental to plant biology and have been indispensable for the conquest of plant life on land. One such core family is microR159 (miR159), which has now been extensively studied in multiple, diverse plant species. In this review, we will highlight the major functions identified for miR159, its use as a model for gaining greater insights into miRNA biology in general, and finally highlight the many outstanding questions surrounding this ancient gene regulator.

\section{MiR159 is Strongly Conserved and Highly Abundant Throughout the Plant Kingdom}

Surveys of the many deep sequencing experiments on the small RNA fractions of plants, find miR159 ubiquitously present as a 21 nucleotide (nt) miRNA in all eudicots and monocotyledonous plants examined [2], and present in the majority of basal angiosperms, gymnosperms, ferns, and lycopods examined [3]. It has either been classified as a Class I (ubiquitous) or a Class II (present in most taxonomic groups) miRNA [2,3]. There is some uncertainty regarding whether miR159 is present in Bryophytes, where it is generally regarded as being absent [4], but it has been reported in a liverwort [5]. However, the reported miR159 sequence was only $18 \mathrm{nt}$ long, suggesting it may not be a genuine miR159 homologue, so further analyses will be required to resolve this. Nevertheless, it is apparent that miR159 arose early in basal land plants and has been strongly conserved henceforth. 
MiR159 fits the curious observation that the stronger the miRNA is conserved, the greater its expression or abundance [2]. This was derived from a multitude of small RNA-sequencing experiments from a wide diversity of plant species, where miR159 is often among the most abundant small RNA species (e.g., [6-10]). Additionally, highly similar miR159 isoforms are present in most land plants (Figure 1; [11]), so the sequence of this canonical miR159 appears to have remained fixed for 100s of millions of years. Nevertheless, like most miRNA families, considerable variation exists within small RNAs defined as miR159, with most plant species containing multiple family members that encode identical or highly similar isoforms, or "isomiRs", that differ by one to several nucleotides. For example, maize has 11 different MIR159 loci, encoding four different miR159 isoforms [12]. For the most part, nucleotide variation occurs at the extremities of the miRNA, at positions considered less important for its specificity [13]. This is the case for the three different miR159 isoforms found in Arabidopsis that vary by 1-2 nucleotides; however, as these isoforms appear functionally redundant, this variation unlikely impacts which genes they target for repression $[14,15]$. Some species have even more variant miR159 isoforms (e.g., poplar; grape, soybean, and maize with 3-5 sequence variations [16]), so whether these miR159 variants have sub-functionalized to regulate different targets remains a possibility. Indeed, the ancient miRNA miR319 is closely related to miR159. In Arabidopsis, these two families are identical at 17 of 21 nucleotide positions, but have distinct target genes, demonstrating their sub-functionalization [17]. Their similarity extends to their primary-MIRNA precursors, where pri-MIR159 and pri-MIR319 are both unusually long fold-back structures that are processed in a non-canonical loop-to-base direction [18]. Phylogenetic analysis of primary-MIRNA precursor sequences of these families supports a common origin of miR319 and miR159, with the likelihood that miR159 has arisen and specialized from miR319 in basal land plants [19].

\section{GAMYB and GAMYB-like Genes are the Only Conserved Targets of miR159}

Core to understanding the function of a miRNA is the identification of the genes that they target. A clear and recurrent theme is that miR159 targets a family of genes encoding R2R3 MYB transcription factors referred to as "GAMYB" or "GAMYB-like". Similar to the conservation of miR159, GAMYB-homologues with a highly conserved miR159 binding site are found in most lineages of land plants (Figure 1). This extends to basal plants such as lycopods (e.g., Selaginella moellendorffii), moss (e.g., Physcomitrella patens), and the liverwort Marchantia polymorpha [20,21]. However, in Marchantia it appears that the GAMYB homologue is not regulated by miR159, but rather by miR319 [21,22]. Even in Arabidopsis, miR319 can regulate the GAMYB targets [17]. However, as miR319 in Arabidopsis is narrowly and weakly expressed compared to the widely and abundantly expressed miR159, miR319-mediated regulation of the GAMYB-like genes is insignificant relative to miR159-mediated regulation [17]. This makes miR159 functionally specific for the GAMYB-like targets, whereas miR319 is functionally specific for genes encoding another class of transcription factors, the TCP family, which miR159 is unable to regulate $[17,23]$. Therefore, it appears likely the more specific miR159 has arisen from miR319 in basal land plants, sub-functionalizing to become specific for the GAMYB-like genes. Although there is sequence variation in both the miR159 and its binding site within the GAMYB-like genes, both have appeared to have become fixed, arguing that this ancient miR159-GAMYB target relationship is critical for the life of land plants [24].

Strong experimental evidence supports the prediction of conserved miR159-mediated regulation of GAMYB. Firstly, degradome analysis from multiple diverse species confidently identifies GAMYB homologues are being regulated via a miR159-mediated cleavage mechanism. Although this analysis only detects targets regulated by the miRNA-guided cleavage mechanism (and not the translational- repression mechanism), functionally important targets appear to be preferentially detected [25]. Degradome experiments have been mainly performed on higher plants, including eudicots such as Arabidopsis [25], soybean [26], cotton [27], tomato [28], orchids [29], and peach [30]; also monocots such as wheat [31], rice [32], and barley [33], among many others, all of which experimentally validate GAMYB homologues as targets of miR159. Although many of these degradome experiments also pick up other target genes 
(e.g., $[27,31])$, these other targets are diverse in their identity and do not appear to be broadly conserved miR159 targets; i.e., they are not identified in degradomes from multiple diverse species. This argues that although miR159 may regulate additional targets, this does not appear to be at the expense of its main target, GAMYB. For instance, in tomato, miR159 has acquired a novel target, a gene that encodes a protein with a NOZZLE-like domain, and this miR159-mediated regulation is important for tomato development [34]. However, miR159 still regulates GAMYB-like genes in tomato, which is important for fruit development [35].

\title{
5 `-AUCUCGAGGGAAGUUAGGUUU- Lycopod 5 ` -AUCUCGAGGGAAGUUAGGUUU-Fern 5 `-AUCUCGAGGGAAGUUUGGUUU - Pine 5 `-AUCUCGAGGGAAGUUAGGUUU-Amborella 5 `-AUCUCGAGGGAAGUUAGGUUU - Dicots 5 `-AUCUCGAGGGAAGUUAGGUUU-Monocots

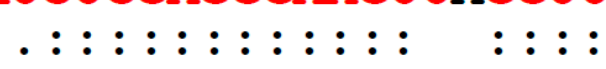 \\ 3 `UGGAGCUCCCUUCAAGCCAAU - Lycopod 3 -GGGAGCUCCCUUCAGUCCAAU - Fern 3 `-UGGAGCUCCCUUCAAGCCAAC - Pine 3 `-UGGAGCUCCCUUCACUCCAAU - Amborella 3 `-UGGAGCUCCCUUCACUCCAAU - Dicots 3 `-UGGAGCUCCCUUCACUCCAAG - Monocots \\ miR159 \\ miRNA binding site in target GAMYB homologue
}

\begin{abstract}
Figure 1. The microR159 (miR159)-GAMYB regulatory pathway appears highly conserved in land plants. Similar/identical miR159 isomiRs (shown in red) are found in most plant linages, including Lycopods (Selaginella uncinata; [3]) ferns (Salvinia cucullata; [3]), pine (Pinus densata; [36]), Amborella [37], dicots, and monocots (miRbase; [11]). Highly similar and complementary miR159 binding sites (shown in blue) are found in GAMYB homologues from lycopods (Selaginella moellendorffii; [20]), ferns (Salvinia cucullata; [11]), pine (Larix kaempferi; [38]), Amborella and many different monocots and dicots. Variant nucleotide positions are shown in black. However, throughout the plant kingdom, variation is not limited to these positions; for example, see [39].
\end{abstract}

\section{The miR159-GAMYB Pathway in Arabidopsis}

The Arabidopsis miR159 family has been extensively studied as a model for plant miRNA-mediated gene regulation (Figure 2). Arabidopsis has three MIR159 genes (MIR159a, MIR159b, and MIR159c), each encoding a distinct isoform that differ from one another by 1-2 nucleotides [8]. Examination of their expression domains with promoter: GUS constructs found MIR159a: GUS and MIR159b: GUS had highly similar expression patterns, being broadly expressed throughout the plant, but strongest in shoot and root meristematic regions [14]. By contrast, the expression domain of a MIR159c: GUS reporter gene was much narrower, being restricted mainly to anthers and the shoot apical region [15], suggesting sub-functionalization. Regarding their level of expression, both deep sequencing and qPCR has found miR159a to be the most abundant family member, with miR159c being very weakly expressed $[8,15]$. To investigate their function, T-DNA loss-of-function mutant alleles were generated for each gene, however, none of the single mir159 mutant plants displayed any phenotypic defects [14,15]. However, consistent with the highly similar expression domains, miR159a and miR159b were demonstrated to be functionally redundant, as a double mir159a.mir159b (mir159ab) mutant displayed severe growth and developmental defects, most notably a smaller rosette with upwardly curled leaves (Figure 2; [14]). 
As a triple mir159abc mutant appeared indistinguishable from mir159ab, this and other data suggested miR159c in Arabidopsis has little to no activity and possibly corresponds to a pseudogene [15,17]. This is one of the few instances in Arabidopsis where T-DNA mutants have been identified and combined for all members of a miRNA family, and the mir159ab and mir159abc mutants have been used extensively in the functional characterization of miR159.

A bioinformatic search of miR159 targets in Arabidopsis using the standard target prediction program psRNATarget, identifies almost 100 potential miR159 targets with four or less mismatches [40]. The top twenty targets are shown in Table 1, which includes eight $M Y B$ genes with highly conserved miR159 binding sites [15]. By contrast, the non-MYB genes are highly diverse and their miR159-binding sites do not appear conserved [15]. Of the conserved $M Y B$ targets, seven are GAMYB-like genes (MYB33, MYB65, MYB81, MYB97, MYB101, MYB104, and MYB120), and the other is non-GAMYB-like gene, DUO1 (DUO POLLEN1), which has a conserved miR159 binding site at a position distinct from the GAMYB-like genes [17]. Despite the fact that miR159-mediated cleavage products can be isolated for many of these predicted targets (Table 1), transcript profiling of the mir159ab mutant only identified two genes that appeared strongly de-regulated, the GAMYB-like targets, MYB33 and MYB65 (Table 1). This de-regulation resulted in MYB33 and MYB65 being strongly expressed throughout the plant $[14,41]$. Consistently, the only genes detected in multiple degradome analyses were MYB33 and MYB65 (Table 1) [25,42]. Eliminating the expression of these genes via the introduction of myb33 and myb65 loss-of-function alleles, suppressed all vegetative phenotypic defects of mir159ab, as a mir159ab.myb33.myb65 quadruple mutant appeared indistinguishable from wild-type, other than male sterility [14]. The phenotype of male sterility is the only apparent defect of myb33.myb65 plants, as MYB33 and MYB65 are two redundant genes that facilitate anther development (Figure 2) [43].

These genetic experiments demonstrated the major role of miR159 in Arabidopsis as being the widespread suppression of MYB33 and MYB65 expression, whose activity has severe deleterious impacts on plant growth and development, including stunted growth and curled leaves (Figure 2). The experiments also defined the functional specificity of miR159 in Arabidopsis as being MYB33 and $M Y B 65$ [14]. Supporting this is the expression of either a miR159-resistant MYB33 or miR159-resistant MYB65 transgene, both of which can phenocopy the mir159ab mutant $[14,23,44]$. This much narrower functional specificity compared to the bioinformatic prediction of many more targets is a common theme in miRNA biology, where both in animal and plants, pleiotropic defects of miRNA mutants can be suppressed via the repression of one-two target genes, despite bioinformatic programs predicting many targets with conserved miRNA binding sites [24,45]. Partially explaining this phenomenon for miR159, many of the bioinformatically predicted miR159 targets appear to have transcriptional domains that are mutually exclusive to that of miR159. Hence, the miRNA and targets are physically separated spatially and/or temporally preventing interaction (Figure 2) [14,15].

Despite their deleterious impact on vegetative growth, MYB33 and MYB65 appear ubiquitously transcribed throughout the plant, but only to be strongly and ubiquitously silenced, other than in seeds and anthers (Figure 2) [41,46]. There are multiple lines of evidence supporting this claim; (1) the vegetative phenotype of myb33.myb65 appears indistinguishable from wild-type; (2) the transcriptome profiles of shoot apical regions of wild-type versus myb33.myb65 appear indistinguishable; (3) the expression of a MYB33: GUS transgene is undetectable in GUS-stained vegetative tissues, but a miR159 resistant version of the reporter gene, $m M Y B 33$ : GUS, is widely and strongly expressed (Figure 2) [41]. The efficiency of this silencing is highlighted by the mir159a single mutant; although deep sequencing demonstrates miR159a is the predominant isoform (e.g., miR159a-6621 reads, miR159b-982 reads [8]), the mir159a mutant appears indistinguishable from wild-type [14], implying strong reductions in miR159 levels do not impact the silencing of MYB33/MYB65. Conversely, overexpression of a wild-type $M Y B 33$ gene fails to result in any phenotypic defects [47]. Although these MYB33 overexpressing Arabidopsis plants have high MYB33 mRNA levels, they do not exhibit any phenotypic defects, indicating miR159 also represses expression of MYB33/MYB65 mRNA via a translational repression mechanism [47]. The importance of this mechanism was shown via the complementation of mir159ab 
with a mutated miR159 variant that had two mismatches to MYB33/MYB65 at the cleavage site; although this attenuated cleavage, this miR159 variant could still potently silence MYB33/MYB65 [47]. Therefore, these combined silencing mechanisms ensure MYB33/MYB65 are strongly repressed in vegetative tissues.

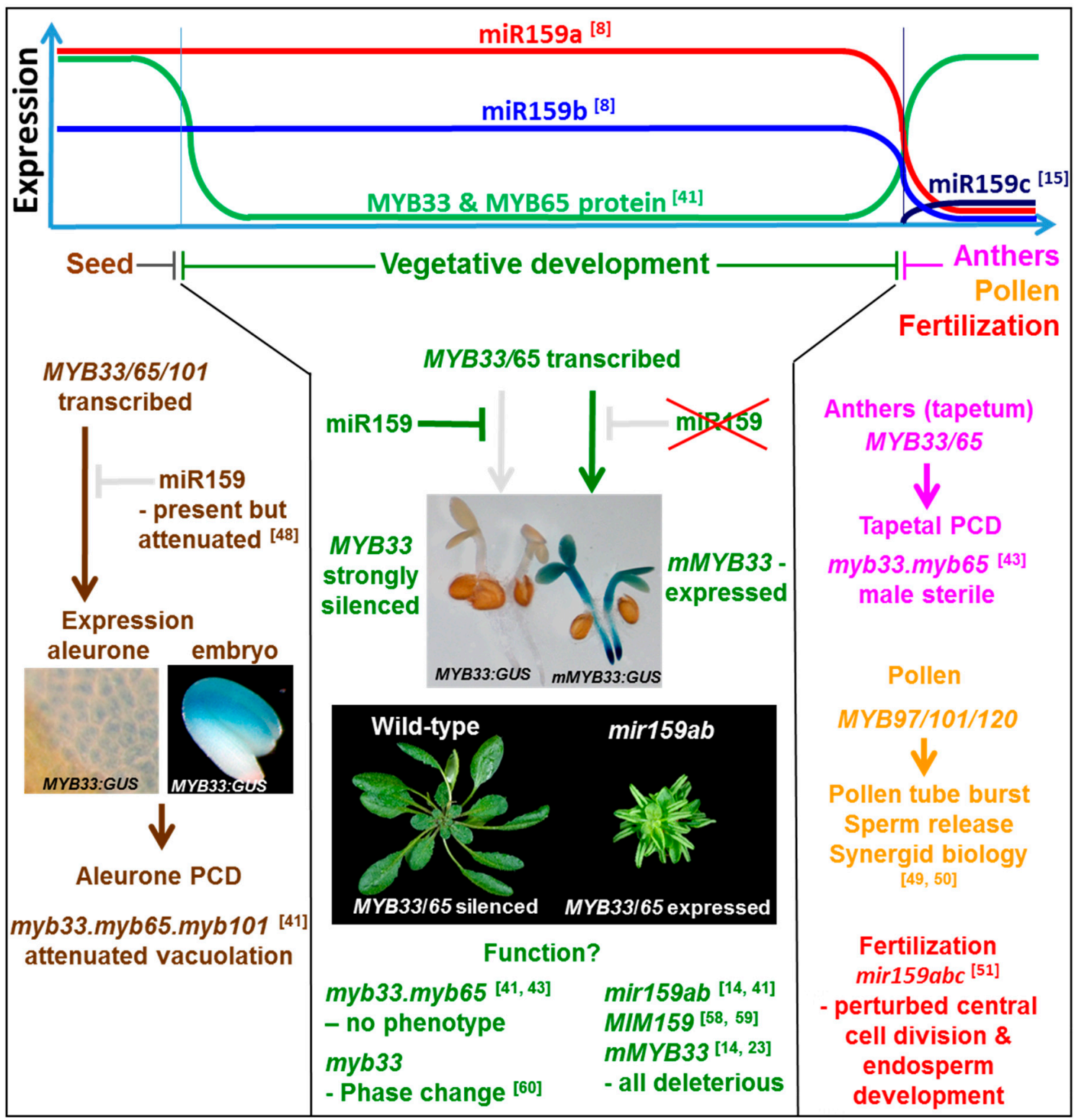

Figure 2. The miR159-GAMYB-like pathway in Arabidopsis. miR159a is the predominant family member, being expressed in seed and throughout plant development at a constantly high level, but it is absent in anthers $[8,14,46]$. miR159b is expressed at a lower level than miR159a $[8,15,46]$, but its expression pattern appears highly similar to miR159a [14]. miR159c, is weakly expressed and appears mainly confined to anthers [15]. In seeds, miR159 efficacy appears attenuated [48], enabling GAMYB-like gene expression which promotes PCD of the aleurone [41]. In contrast, throughout vegetative development, miR159 efficacy is strong, and MYB33/65 expression is strongly silenced. Only via inhibition of miR159, or mutation of the miR159 binding site within MYB33 or MYB65, will expression occur, which leads to strong deleterious outcomes, such as stunted growth and curled leaves [14,41]. Although the function of the pathway has been suggested to be involved in flowering-time and phase change, the purpose of this pathway in vegetative development is still unclear. In anthers, miR159 activity is low. Here, MYB33 and MYB65 are expressed to promote PCD in the tapetum [43]. MYB97/101/120 expression is required for pollen function [49,50]. Finally, miR159 is required for fertilization [51]. 
Table 1. miR159 targets in Arabidopsis as determined by different approaches. The top 20 miR159a targets in Arabidopsis as identified by the bioinformatic program psRNATarget with standard search parameters [40]; the number of mismatches is indicated by the score. Confirming this prediction, $5^{\prime}$-RACE analysis can detect miR159-guided cleavage products for at least nine of these genes. In contrast, the more quantitative degradome analysis only identifies three of these genes, with only MYB33 and MYB65 being frequently detected in multiple degradome analyses [25,42]. Overexpression of miR159 could detect down-regulation of multiple targets [13,52]. However, genetic analysis using a loss-of-function mir159ab mutant identify MYB33 and MYB65 as the major important targets [14,41].

\begin{tabular}{cccccccc}
\hline & At Number & Score & Name & 5'-RACE & Degradome & miR159 OE & miR159ab \\
\hline 1 & AT4G37770 & 1.5 & ACS8 & {$[53]$} & & {$[13]$} & \\
2 & AT2G32460 & 2 & MYB101 & {$[15,17,53]$} & & {$[13]$} & \\
3 & AT3G60460 & 2 & DUO1 & {$[15,17,53]$} & & \\
4 & AT2G26950 & 2 & MYB104 & & & \\
5 & AT4G26930 & 2 & MYB97 & & & \\
6 & AT5G06100 & 2.5 & MYB33 & {$[15,23]$} & {$[25,42]$} & {$[52]$} & {$[14,41]$} \\
7 & AT3G11440 & 2.5 & MYB65 & {$[23]$} & {$[25,42]$} & & \\
8 & AT2G34010 & 2.5 & MRG1 & {$[53]$} & {$[42]$} & & \\
9 & AT2G21600 & 2.5 & RER1B & & & \\
10 & AT5G55020 & 2.5 & MYB120 & {$[15]$} & & \\
11 & AT4G27330 & 2.5 & SPL & & & \\
12 & AT5G27395 & 2.5 & Tim44-related & & & \\
13 & AT3G61740 & 3 & SDG14, ATX3 & & & \\
14 & AT1G29010 & 3 & MRG-LIKE & & & \\
15 & AT4G31240 & 3 & NRX2 & & & \\
16 & AT2G26960 & 3 & MYB81 & {$[15]$} & & \\
17 & AT2G22810 & 3 & ACS4 & & & \\
18 & AT3G08850 & 3 & RAPTOR1B & & & \\
19 & AT5G55930 & 3.5 & OPT1 & {$[13]$} & & \\
20 & AT2G44450 & 3.5 & beta gluc 15 & & & \\
\hline
\end{tabular}

\section{Conserved RNA Secondary Structures in MYB33/65 Promote miR159-Mediated Silencing}

Highlighting this efficient silencing were miR159 efficacy assays performed on the various Arabidopsis $M Y B$ targets [44]. Here, it was demonstrated that $M Y B 33$ and $M Y B 65$ were very sensitive targets of miR159, being strongly silenced. In contrast, the other MYB genes (MYB81, MYB97, MYB101, MYB104, and DUO1), were poorly silenced by miR159. As all these MYB targets had highly complementary miR159 binding sites, it implies factors other than complementarity must be contributing to this differential miR159-mediated silencing [44]. Correlating with this difference, is a predicted RNA secondary structure that abuts the miR159 binding site of MYB33 and MYB65, but which is absent in the poorly regulated targets (Figure 3; also see [44] for RNA secondary structures of the various Arabidopsis GAMYB-like genes). To determine the significance of this in silico predicted RNA structure, a structure/function analysis was performed. Mutation of this structure within the MYB33 context attenuates silencing, whereas the restoration of the structure, although with a different primary nucleotide sequence, restores strong silencing of MYB33 [44]. Therefore, this demonstrates that this RNA secondary structure facilitates MYB33 and MYB65 silencing, earmarking them as functional targets of miR159. It argues that a fully functional miR159 target site of MYB33/MYB65 encompasses nucleotides beyond that of the binding site.

Further evidence of the importance of this RNA secondary structure is its strong conservation in GAMYB-like homologues throughout the plant kingdom (Figure 3), as the nucleotides that correspond to the stems of the RNA secondary structures are conserved in GAMYB homologues of eudicots, monocots, and basal angiosperms, such as Amborella [44]. This indicates this structure is part of the miR159-GAMYB regulatory relationship and that the mechanism of regulation is likely more complex than miRNA-binding site complementarity alone. Given that so many miRNA-target relationships are ancient, it will be interesting to investigate how many other miRNA targets have conserved RNA 
elements associated with their miRNA binding sites, as these ancient regulatory relationships have had 100s of millions of years to evolve greater regulatory complexity.

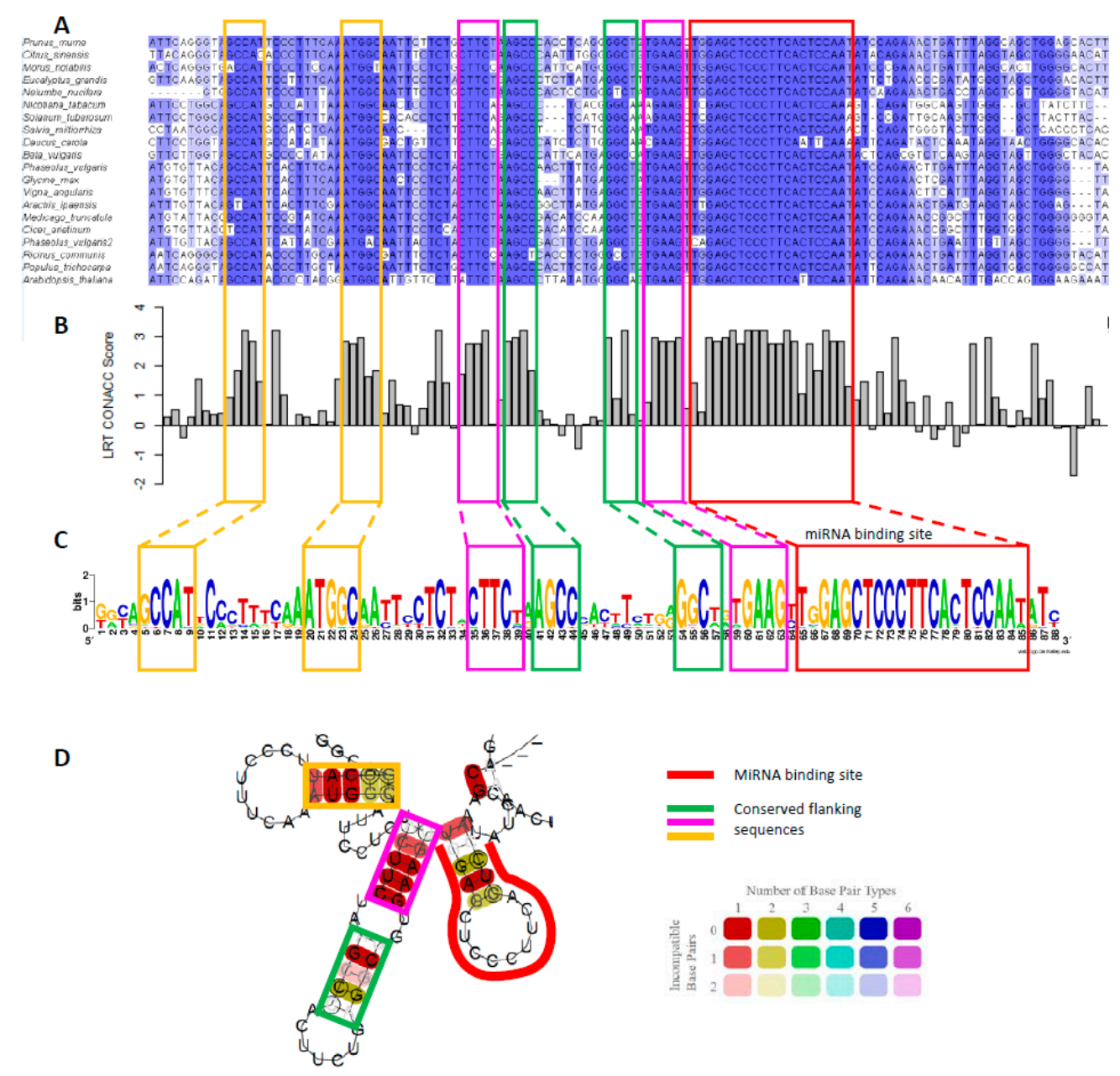

Figure 3. (A) Multiple alignment of $M Y B 33$ homologues from different plants species. The binding site is boxed in red, and the conserved flanking sequences in yellow, pink, and green throughout the Figure. (B) phyloP score of the multiple sequence alignment of $M Y B 33$ sequences. A positive score denotes evolutionary conservation, whereas, a negative score denotes acceleration [54]. A likelihood ratio test (LRT) was used as the method to detect non-neutral substitution rates. Scores were generated using rPHAST [55]. (C) Sequence logo of the binding site and conserved flanking sequences generated using WebLogo [56]. (D) RNA secondary structure prediction of the consensus sequence from the multiple alignment in A. generated using RNAalifold [57] at $22{ }^{\circ} \mathrm{C}$ and default parameters. Colours represent the number of base pairs types (i.e., $\mathrm{AU}, \mathrm{UA}, \mathrm{CG}, \mathrm{GC}, \mathrm{UG}, \mathrm{GU})$, and hue the number of non-conserved nucleotides at that position.

In Arabidopsis, not only do the poorly regulated GAMYB-like genes lack this conserved RNA structure, but they have highly specific transcriptional domains, predominantly in seeds and anthers, where miR159 activity appears attenuated or absent $[14,15,49,50]$. Therefore, strong selection of this RNA secondary structural element may have occurred for GAMYB homologues that are transcribed in vegetative tissues and require strong miR159-mediated silencing to prevent deleterious outcomes [44]. Investigating whether this also applies to other species with multiple GAMYB homologues will be interesting to follow up. Finally, the efficacy of miR159-mediated silencing of MYB33 in Arabidopsis varies between tissues, being strong in the rosette, but weak in the seed [48]. As RNA secondary structures are dynamic in vivo, they may be operating as a riboswitch, with certain formations facilitating silencing, 
and others attenuating silencing. It will be interesting to determine whether the conformation of the RNA secondary structure changes between tissues, controlling the ability of miR159 to silence MYB33.

\section{The Function of miR159-MYB Pathway in Plant Development}

The functional role of the miR159-GAMYB pathway has been studied in numerous plant species, and this is summarized in Table 2.

Table 2. Functional analyses of the miR159-GAMYB pathway in plants.

\begin{tabular}{|c|c|c|c|}
\hline Species & Approach & Phenotype & Ref. \\
\hline Arabidopsis & T-DNA mir159ab mutant & $\begin{array}{l}\text { Pleiotropic defects, stunted growth, curled leaves, } \\
\text { reduced apical dominance }\end{array}$ & [14] \\
\hline Arabidopsis & T-DNA mir159c mutant & none & [15] \\
\hline Arabidopsis & T-DNA mir159abc mutant & Perturbed fertilization & [51] \\
\hline Arabidopsis & MIM159 mimic-loss-of-function. & $\begin{array}{l}\text { Pleiotropic defects, stunted growth, curled leaves, } \\
\text { defective sepals, petals and anthers }\end{array}$ & {$[58,59]$} \\
\hline Arabidopsis (Col-0) & miR159a overexpression & Male sterility & [13] \\
\hline Arabidopsis (Ler) & miR159a overexpression & Male sterility, delayed flowering-time & [52] \\
\hline Arabidopsis & T-DNA myb33.myb65 mutant & Male sterile & [43] \\
\hline Arabidopsis & T-DNA myb33 mutant & Altered phase change & [60] \\
\hline Rice & STTM159 mimic-loss-of-function & Stunted growth, curled leaves, smaller seeds & {$[61,62]$} \\
\hline Rice & miR159 overexpression & $\begin{array}{l}\text { Delayed heading, shorten internode I, malformed flowers, } \\
\text { male sterility }\end{array}$ & {$[63]$} \\
\hline Rice & gamyb-1 insertion mutant & Male sterility & [64] \\
\hline Barley & miR159 overexpression & Male sterility & [65] \\
\hline Wheat & miR159 overexpression & Delayed heading, male sterility, increased tillering & {$[66]$} \\
\hline Gloxinia & $\begin{array}{l}\text { MIM159 mimic loss-of-function, } \\
\text { miR159 over-expression (OE) }\end{array}$ & $\begin{array}{l}\text { Accelerated flowering (MIM159) or delayed flowering } \\
\text { (miR159 OE) }\end{array}$ & [67] \\
\hline Tomato & miR159 overexpression & Fruit set, parthenocarpy, ovule development, seedless fruits & [35] \\
\hline Cucumber & RNAi against $G A M Y B$ & Altered ratio of male to female flowers & [68] \\
\hline Strawberry & RNAi against $G A M Y B$ & Inhibition of receptacle ripening & [69] \\
\hline
\end{tabular}

\subsection{A Role in Male Reproductive Development}

The GAMYB/GAMYB-like family of transcription factors is found throughout the plant kingdom, where they share high sequence similarity in their R2R3 DNA-binding domains located towards the $\mathrm{N}$-terminal region, but are much more diverse in their C-terminal regions [20]. Nevertheless, the functions of these GAMYB homologues appear to be highly conserved, as GAMYB homologues from Lycopods or Bryophytes can partially complement a gamyb-2 rice mutant [20], or a cucumber GAMYB can complement the male sterile phenotype of the Arabidopsis myb33.myb65 mutant [68]. Hence, despite the sequence diversity of the C-terminal regions, this complementation of distant species argues the biochemical function of GAMYB has been strongly conserved.

To date, a role in male reproductive development appears the clearest function for GAMYB [70]. Inhibition of its activity perturbs male development, whether in basal plants such as lycopods (Selaginella moellendorffii) or bryophytes (moss-Physcomitrella patens) [20], or in higher flowering plants, such as rice [64] or Arabidopsis [43]. Moreover, GAMYB was shown to positively regulate the CYP703 gene, which is required for male development in both basal and higher plants [20,71]. It appears this GAMYB-CYP703 pathway arose very early in land plant development, and then has come under the control of gibberellin (GA) in lycopods, likely explaining why male reproductive development in plants is under the control of GA [20,71]. It was speculated that the GA regulation of the GAMYB-CYP703 pathway was a step in the evolution of the sporophyte-dominated life cycle, which requires greater regulatory control for its more complex reproductive system [20].

Consistently, there have been many reports of plants with multiple GAMYB homologues for which at least one is strongly transcribed in anthers (e.g., CSGAMYB1 in cucumber, [68]; TaGAMYB1 in wheat, [66]; HvGAMYB in barley, [65]), or is anther-specific (e.g., PtrMYB012 in poplar, [16]; MYB97, MYB120 in Arabidopsis, [49]), many of which are positively regulated by GA. Inhibition of GAMYB activity perturbs programmed cell death (PCD) in the anther tapetum [71], where in both a rice gamyb mutant, and the Arabidopsis myb33.myb65 mutant, the tapetum fails to degenerate, resulting 
in hypertrophy, leading to male sterility [43,64,71]. Additionally, MYB33 and MYB65 in Arabidopsis are also required for the formation of the radial microtubule array surrounding nuclei immediately following meiosis II [72]. In the myb33.myb65 mutant, the resulting defects in male meiotic cytokinesis produce diploid pollen with a defective pollen wall morphology [72]. However, the role that miR159 plays in regulating GAMYB expression in male development is unclear, where it may be fine-tuning expression or preventing expression occurring in particular cell layers, but for most species, this is yet to be resolved. In rice anthers, miR159 and GAMYB are co-expressed, suggesting potential fine-tuning of GAMYB expression [63].

In Arabidopsis, the role of the miR159-GAMYB pathway and its interaction with the miR319-TCP pathway in flower maturation has been investigated using miRNA loss-of-function MIM159 and MIM319 transgenic plants, both of which display multiple pleiotropic defects [59]. In sepals, petals and anthers of these plants, it was found that the GAMYB and TCP proteins are expressed and directly interact to regulate another miRNA, miR167, which creates a miR159-miR319-miR167 network. It is proposed that the function of miR159/miR319 is to dampen MYB/TCP expression, resulting in low miR167, and hence enabling strong ARF6/8 expression, which in turn regulates many genes required for floral development including that of auxin signaling [59]. However, in wild-type plants, it appears MYB33/65 expression in flowers is restricted to anthers, and the myb33.myb65 mutant only displays anther defects [43]. Therefore, in wild-type, it appears the role of miR159 in flowers is to strongly repress the $M Y B$ genes in sepals and petals to prevent strong expression of miR167 to ultimately enable strong ARF6/8 expression.

MiR159 is present in pollen where it has a crucial role in fertility [51]. It has been known for some time that sperm cell entry alone triggers central cell division, suggesting that the male genome and/or unknown factors transmitted by the sperm control the initiation of endosperm development. Unexpectedly, the central cell usually fails to initiate division after pollination by mir159abc mutants, or stops dividing after one or two divisions, resulting in reduced seed set. It was found that both MYB33 and MYB65 are highly expressed in the central cell of the embryo sac before fertilization, but after fertilization, both transcripts are rapidly cleared from the central cell and the endosperm initiates development. It was observed that MYB33 and MYB65 transcripts are not cleared in pollinations with mir159abc pollen, suggesting that miR159 in pollen is transmitted to the central cell by fertilization where it degrades MYB33 and MYB65 transcripts [51]. Thus, miR159 has a paternal effect on seed development: miR159 carried in pollen abolishes central cell repression after fertilization permitting endosperm nuclear divisions [51]. Loss of maternal miR159 also results in seed defects but these defects are less severe on seed set than loss of paternal miR159, and the mechanism of this maternal effect is unknown.

\subsection{A Role in Seed Development}

GAMYB was first identified as a GA signaling component in the barley aleurone, hence giving these MYB genes their name "GA"MYB [73]. Here, GAMYB positively transduces the GA signal to activate expression of $\alpha$-amylase and other hydrolytic enzymes [74], as well as promote PCD in the aleurone [75]. This latter function appears conserved in Arabidopsis, as a myb33.myb65.myb101 triple mutant has attenuated vacuolation in aleurone cells, a PCD-mediated process that is positively regulated by GA [41]. Therefore, a conserved role in PCD in the aleurone and tapetum in both monocots and dicots is currently a unifying function for these GAMYB transcription factors. Curiously, both these tissues are single cell layers that provide nutrients upon death to the embryo (aleurone) or pollen (tapetum). It is possible other GAMYB-like genes may play similar roles in terms of inhibiting growth and promoting cell death. For example, MYB97, MYB101, and MYB120 are all expressed in the pollen tube, and in a myb97.myb101.myb120 mutant, the pollen tube fails to undergo growth arrest and then fails to degenerate in order to release the sperm cells to the ovules $[49,50]$.

Many downstream targets of the miR159-GAMYB pathway in Arabidopsis support a role in PCD. Micro-array analysis on the shoot apical region of mir159ab plants found that of the 166 up-regulated genes, 
many appeared aleurone related [41]. Many of these aleurone related genes were also down-regulated in myb33.myb65.myb101 seeds, making them strong candidates of being downstream of GAMYB activity [41]. This includes the most up-regulated gene in mir159ab, CYSTEINE PROTEINASE 1 (CP1), whose expression appears tightly correlated with GAMYB expression [41,46], and corresponds to a class of enzymes which have been associated with PCD and cell lysis. Similarly, inhibition of miR159 in transgenic rice results in up-regulation of pathways associated with $P C D$, suggesting that GAMYB promotes these pathways in the rice grain [61]. Again, what role miR159 plays in regulating GAMYB activity in the seed is unclear. In Arabidopsis germinating seeds, miR159 and MYB33 are co-transcribed in the aleurone and embryo, however, MYB33 protein is expressed, which suggests miR159 may only be fine-tuning the expression of MYB33 in this tissue [48]. Nevertheless, mir159ab plants produce malformed seeds [14], implying miR159 is required for proper seed development.

\subsection{The Role of miR159-GAMYB Pathway in Vegetative Tissues}

In Arabidopsis, the widespread transcription of $M Y B 33 / M Y B 65$, only to be strongly silenced by miR159 raises the question of what is the purpose of this seemingly futile regulatory pathway. Although miR159 is sometimes associated with leaf development due to the smaller, upwardly curled leaves of the mir159ab mutant (Figure 2), this phenotype appears more a consequence of the deleterious impact of MYB33/MYB65 expression rather than the alteration of a developmental program [41]. In general, de-regulated expression of GAMYB in leaves results in strong perturbation of growth. This was shown in mir159ab, as well as transgenic Arabidopsis expressing miRNA decoys to inhibit miR159 function, either MIMIC159 (MIM159), Short target tandem MIMIC159 (STTM159), or SPONGE159 (SP159) [58,76], or with STTM159 rice [61,62], which all result in the similar phenotypic defect of stunted growth. For instance, STTM159 rice plants are shorter than wild-type rice, with decreased cell numbers, and the most down-regulated genes in STTM159 rice are associated with cell division. Therefore, the main role of rice miR159 is to suppress GAMYB expression to enable cell proliferation [61]. Likewise, the expression of miR159-resistant GAMYB transgenes in Arabidopsis [14,16,23,44], lead to the same phenotypic defects. Therefore, it is clear that these GAMYB genes encode a class of transcription factors that when expressed inhibit growth, a phenotype contrary to a role in promoting the GA signal for which they were originally identified. Supporting this, GA treatments do not alter the RNA levels of MYB33, MYB65 or miR159 in Arabidopsis rosettes, and the response of myb33.myb65 plants to GA is not perturbed in vegetative tissues [41]. Therefore, the role the GAMYB in transducing the GA signal appears to be tissue dependent, where it is involved in transducing the GA signal in seeds and anthers [70,73,77], but not in vegetative tissues [41]. Supporting this, the Arabidopsis myb33.myb65 or rice gamyb mutants do not appear to have any obvious phenotypic defects at the vegetative stage [43,64].

Contrary to the growth inhibition phenotype of the leaves, the roots of mir159ab Arabidopsis are longer than wild-type and have a larger apical meristem zone. Thus, in roots, GAMYB expression appears to enhance cell cycle progression, leading to extended roots. However, the root lengths of myb33.myb65 or myb33.myb65.myb101 plants were unchanged compared to wild-type, again indicating that these GAMYB-like genes are likely fully silenced in roots, again raising the question of what is the role of this pathway in this vegetative tissue [78].

\subsection{A Role of miR159 in Controlling GA-Mediated Flowering-Time and Growth?}

This clear role in inhibiting growth appears at odds with a role often ascribed to GAMYB in promoting flowering-time $[79,80]$. This idea arose from the fact that GA promotes flowering-time, and that the GAMYB or GAMYB-like genes were thought to be positive regulators of GA throughout the plant [81]. Supporting this idea was the finding that the LEAFY gene, a central regulator of flowering, contained a MYB-binding site within its promoter, and this binding site appeared critical in transducing the GA-signal [82]. Subsequently, it was shown that MYB33 transcription was induced at the shoot apical region upon the induction of flowering, either through GA-application or exposure to long-day conditions, and that the MYB33 protein could bind the LEAFY promoter in in vitro gel shift 
assays [81]. Then, overexpression of miR159 in Arabidopsis [ecotype Landsberg erecta, (Ler)] resulted in down-regulation of MYB33 expression, which correlated with a decrease in LEAFY expression and a delayed flowering-time under short-day conditions [52]. Supporting this is the manipulation of miR159 levels in other plant species that result in altered flowering-times. This includes overexpression of miR159 in rice and wheat which lead to a reduced heading-time [63,66]. Additionally, in the ornamental flowering plant Gloxinia, the over-expression of miR159 delayed flowering, whereas the inhibition of miR159 with a MIM159 transgene accelerated flowering-time [67]. Unlike MIM159 Arabidopsis or STTM159 rice [58,59,61,62,76], MIM159 Gloxinia did not exhibit any defects in vegetative growth or development [67].

Such evidence argues for a clear and conserved role for miR159 in flowering-time, and that GAMYB is likely promoting the GA-signal with regard to flowering. However, overexpression of miR159 in Arabidopsis (ecotype Columbia) did not affect flowering-time [13]. So, although overexpression of miR159 in both ecotypes (Ler and Columbia) resulted in male sterility due the requirement of GAMYB activity in anthers, there was a differential response with regard to flowering-time. Moreover, a myb33.myb65 mutant (ecotype Columbia) did not have a delayed flowering-time, and the mir159ab mutant (greater GAMYB activity) displayed a late flowering-time under short-day conditions, implying greater GAMYB activity was inhibiting flowering [41]. Given the severe pleiotropic defects of mir159ab, it is uncertain whether delayed flowering is a direct result of greater GAMYB activity, or a secondary effect of the severe growth and developmental defects [41].

In addition to delayed flowering, the mir159ab Arabidopsis mutant was found to have a strong delay in vegetative phase change (VPC), with the first leaf with abaxial trichomes being leaf 16.0 as opposed to leaf 7.9 for wild-type, and this was tightly correlated with the increased levels of miR156, one of the key determinants of VPC [60]. In a complex regulatory mechanism, it was found that MYB33 activated transcription of both the MIR156 gene and its target, SPL9, via direct interaction with their promoters [60]. Conversely, Arabidopsis plants overexpressing miR159 (leaf 7.3) or the myb33 mutant (leaf 7.1) only had slight increases in VPC compared to wild-type (leaf 7.9). This argued that MYB33 protein is expressed to some extent in the Arabidopsis rosette. However, the VPC of a myb65 mutant (leaf 8.1) was unchanged from wild-type, implying MYB65 did not appear to impact this pathway [60]. Given the subtle changes to vegetative phase change in the myb33 mutant, the miR159-GAMYB pathway was considered a modifier of VPC, where miR159 promotes VPC by preventing MYB33 expression which negatively regulates VPC [60]. It will be interesting to see what role the miR159-GAMYB pathway is found to have in this process in other plant species.

Therefore, regarding the miR159-GAMYB pathway in growth and flowering, there is strong conflicting evidence. Although the difference in Arabidopsis is possibly due to ecotype variation, a role for GAMYB in either promoting flowering, or alternatively, deleteriously inhibiting growth, will need further experimentation for clarification of how such diametrically opposed outcomes can arise.

\subsection{Fruit and Reproductive Development}

There is growing evidence that the miR159-GAMYB pathway plays a role in fruit development. In strawberries, fruit development is GA-regulated, and miR159 is strongly expressed in the fruit's receptacle tissue and appears to regulate $G A M Y B$, as miR159 and GAMYB expression is reciprocal [83]. $G A M Y B$ is a key regulator of strawberry fruit development, as repression of GAMYB via RNAi inhibits receptacle ripening and color formation [69]. In tomato, the miR159-GAMYB pathway is present in ovules, and overexpression of miR159 resulted in abnormal ovule development, precocious fruit initiation and seedless fruits [35]. Similarly, in grapes, the pathway appears active in the fruits, and under the control of GA [84]. In the monoecious plant cucumber, inhibition of GAMYB activity via RNAi altered the ratio of male to female flowers, decreasing the number of nodes with male flowers [68]. Therefore, it appears this pathway is involved in many different functions of the reproductive process in different plant species. 


\section{The Function of the miR159-MYB Pathway in Plant Stress}

\subsection{Abiotic Stress}

Given the ubiquity and abundance of miR159 throughout the plant kingdom, it is not surprising that numerous studies have implicated miR159 in a wide range of stresses from many different plant species (for review see [85]). In Arabidopsis, miR159 levels increase under salinity [86], and in germinating seeds, miR159 has been found to accumulate in response to the stress hormone ABA as well as to drought [87]. MiR159 also accumulates to higher levels in response to drought in maize, wheat and barley [85]. Such results suggests that increased levels of miR159 may result in greater stress tolerance. However, in some species, miR159 levels decrease in response to drought or salinity [85], and overexpression of miR159 in rice resulted in increased sensitivity to heat-stress [66]. In potato, in which the drought tolerant gene cap-binding 80 protein has been down-regulated, miR159 levels were decreased and mRNA levels of GAMYB-like homologues were higher [88]. Therefore, these studies have found no consistent or unified role for miR159 in plant stress response.

The functional role of the Arabidopsis miR159-GAMYB pathway to abiotic stress was investigated by comparing the response a mutant lacking this entire pathway, the mir159ab.myb33.myb65 quadruple mutant, to that of wild-type plants [46]. Two-week old plants were exposed to three weeks of treatments with either ABA, high temperature, high light, drought or cold. However, no differential response between the mir159ab.myb33.myb65 mutant and wild-type plants were identified. As it was demonstrated that miR159 fully represses MYB33 and MYB65 in vegetative tissues of Arabidopsis plants [41], it was rationalized that miR159 levels would need to decrease in Arabidopsis to enable activation of these two GAMYB-like genes [46]. However, none of the treatments appeared to repress miR159 to levels in which would allow MYB33 and MYB65 expression, and this was supported by assaying the downstream marker gene $C P 1$, whose levels appeared completely repressed [46]. Based on this, no clear role for this pathway was identified, and it remains uncertain what role it plays in stress response in Arabidopsis.

\subsection{Biotic Stress}

Similarly, the levels of miR159 respond to many different biotic stresses. Recently it was shown that cotton and Arabidopsis accumulate elevated levels of miR159 in response to the fungus, Verticillium dahlia [89]. MiR159 was exported into the fungal hyphae, where it targeted the gene encoding isotrichodermin C-15 hydroxylase (HiC-15), which is critical for hyphal growth. As expression of a miR159-resistant HiC-15 gene in V. dahlia resulted in greater virulence, it was concluded that exporting miR159 from the plant was conferring greater pathogenic resistance. Given that the miR159-binding site is highly conserved in HiC-15, it was hypothesized that this has evolved to dampen HiC-15 expression as to avoid rapid death of the host, which then enables establishment of the fungus on the plant [89]. Currently, this is the only clear role for miR159 in pathogen response.

MiR159 also accumulates to higher levels in Arabidopsis root galls that form in response to root knot nematodes (RKN). The MYB33 gene appears dynamically expressed during gall formation, as a MYB33: GUS reporter was expressed during early gall development, but not at later stages. Functional evidence for the involvement of the miR159-GAMYB pathway is that an Arabidopsis mir159abc triple mutant has greater resistance to root knot nematodes (RKN) [90]. Further investigation will be needed to understand the precise role of the pathway in gall formation and the response pathway to RKN infection.

\section{Conclusions and Some Unresolved Questions}

The miR159-GAMYB pathway appears nearly ubiquitous in terrestrial plants, implying it has played an important role in plant's conquest of the land. Although its role in some tissues now appear to be relatively clear, this is far from the case in others. Below are some of the questions we believe still need to be resolved.

1. Why are $M Y B 33$ and $M Y B 65$ transcribed in vegetative tissues where failure to fully repress them results in a detrimental effect? What selective advantage does this give the plant? 
a. One hypothesis is that if miR159 is inhibited by a certain trigger, and strong MYB33/65 expression occurs, growth inhibition (or another unknown process) may result in a beneficial outcome (e.g., drought conditions to slow growth). However, currently, no triggers to inhibit miR159 to enable strong $M Y B$ expression are known.

b. A second hypothesis would be that MYB33/65 are not silenced in all vegetative tissues, but in certain cells they are expressed where they confer a selective advantage. Some evidence suggests GAMYB is involved in the transition to flowering, and VPC in Arabidopsis. But currently there is much conflicting data. For instance in Arabidopsis, overexpressing miR159 represses flowering-time, and inhibition of miR159 represses VPC. Other studies have found no role for miR159 in flowering. More work is needed here to clarify these roles, and how conserved they are across species.

2. Why is expression of GAMYB in vegetative tissues deleterious and how does it inhibit growth? What down-stream events are these genes triggering? Although some studies have started to address this, more work is needed for a clearer understanding.

3. Is GAMYB function related to the way it is regulated, i.e., strongly transcribed, only to then be strongly silenced by miR159? Does miR159 have a role in stress response? Again, many studies have identified changes to miR159 levels in response to a host of different biotic/abiotic stresses, but currently there is no clearly defined role for this miR159 concerning stress tolerance/response.

4. How does the conserved RNA secondary structure associated with the miR159-binding sites of GAMYB genes promote their silencing by miR159? Can this structure facilitate a complex regulatory mechanism, enabling strong silencing in some tissues, but poor silencing in others, depending on a dynamic secondary structure configuration? i.e., acting like a riboswitch concerning silencing.

5. What is the role of miR159-mediate regulation on non-GAMYB targets? For example, DUO1 has a conserved miR159-binding site, but the role of miR159 in controlling the expression of this gene remains unclear.

6. What is the role of miR159 in female fertility? Why are Arabidopsis mir159ab seeds small and misshapen (likewise rice STTM159 grains are small)? Why does the central cell still divide in some mir159abc ovules? How can a seed still form (from mir159abc pollen) with a viable embryo when the endosperm divisions stop apparently so early?

Author Contributions: All authors contributed to the writing of the review.

Funding: This research received no external funding.

Acknowledgments: G.W. was supported by an Australian Government Research Training Program RTP Scholarship.

Conflicts of Interest: The authors declare no conflict of interest.

\section{References}

1. Axtell, M.J.; Bartel, D.P. Antiquity of microRNAs and their targets in land plants. Plant Cell 2005, 17, 1658-1673. [CrossRef] [PubMed]

2. Chávez Montes, R.A.; de Fátima Rosas-Cárdenas, F.; De Paoli, E.; Accerbi, M.; Rymarquis, L.A.; Mahalingam, G.; Marsch-Martínez, N.; Meyers, B.C.; Green, P.J.; de Folter, S. Sample sequencing of vascular plants demonstrates widespread conservation and divergence of microRNAs. Nat. Commun. 2014, 5, 3722. [CrossRef] [PubMed]

3. You, C.; Cui, J.; Wang, H.; Qi, X.; Kuo, L.Y.; Ma, H.; Gao, L.; Mo, B.; Chen, X. Conservation and divergence of small RNA pathways and microRNAs in land plants. Genome Biol. 2017, 18, 158. [CrossRef] [PubMed]

4. Axtell, M.J.; Meyers, B.C. Revisiting criteria for plant microRNA annotation in the era of big data. Plant Cell 2018, 30, 272-284. [CrossRef] [PubMed]

5. Alaba, S.; Piszczalka, P.; Pietrykowska, H.; Pacak, A.M.; Sierocka, I.; Nuc, P.W.; Singh, K.; Plewka, P.; Sulkowska, A.; Jarmolowski, A.; et al. The liverwort Pellia endiviifolia shares microtranscriptomic traits that are common to green algae and land plants. Plant J. 2014, 80, 331-344. 
6. Fahlgren, N.; Howell, M.D.; Kasschau, K.D.; Chapman, E.J.; Sullivan, C.M.; Cumbie, J.S.; Givan, S.A.; Law, T.F.; Grant, S.R.; Dang, J.L.; et al. High-throughput sequencing of Arabidopsis microRNAs: Evidence for frequent birth and death of MIRNA genes. PLOS ONE 2007, 2, e219. [CrossRef] [PubMed]

7. Jeong, D.H.; Park, S.; Zhai, J.; Gurazada, S.G.R.; De Paoli, E.; Meyers, B.C.; Green, P.J. Massive analysis of rice small RNAs: Mechanistic implications of regulated microRNAs and variants for differential target RNA cleavage. Plant Cell 2011, 23, 4185-4207. [CrossRef]

8. Rajagopalan, R.; Vaucheret, H.; Trejo, J.; Bartel, D.P. A diverse and evolutionarily fluid set of microRNAs in Arabidopsis thaliana. Genes Dev. 2006, 20, 3407-3425. [CrossRef] [PubMed]

9. Szittya, G.; Moxon, S.; Santos, D.M.; Jing, R.; Fevereiro, M.P.; Moulton, V.; Dalmay, T. High-throughput sequencing of Medicago truncatula short RNAs identifies eight new miRNA families. BMC Genom. 2008, 9, 593. [CrossRef]

10. Mao, W.; Li, Z.; Xia, X.; Li, Y.; Yu, J. A combined approach of high-throughput sequencing and degradome analysis reveals tissue specific expression of microRNAs and their targets in cucumber. PLOS ONE 2012, 7, e33040. [CrossRef]

11. Kozomara, A.; Birgaoanu, M.; Griffiths-Jones, S. miRBase: From microRNA sequences to function. Nucleic Acids Res. 2019, 47, D155-D162. [CrossRef] [PubMed]

12. Zhang, L.; Chia, J.M.; Kumari, S.; Stein, J.C.; Liu, Z.; Narechania, A.; Maher, C.A.; Guill, K.; McMullen, M.D.; Ware, D. A genome-wide characterization of microRNA genes in maize. PLoS Genet. 2009, 5, e1000716. [CrossRef] [PubMed]

13. Schwab, R.; Palatnik, J.F.; Riester, M.; Schommer, C.; Schmid, M.; Weigel, D. Specific effects of microRNAs on the plant transcriptome. Dev. Cell 2005, 8, 517-527. [CrossRef] [PubMed]

14. Allen, R.S.; Li, J.; Stahle, M.I.; Dubroué, A.; Gubler, F.; Millar, A.A. Genetic analysis reveals functional redundancy and the major target genes of the Arabidopsis miR159 family. Proc. Natl. Acad. Sci. USA 2007, 104, 16371-16376. [CrossRef] [PubMed]

15. Allen, R.S.; Li, J.; Alonso-Peral, M.M.; White, R.G.; Gubler, F.; Millar, A.A. MicroR159 regulation of most conserved targets in Arabidopsis has negligible phenotypic effects. Silence 2010, 1, 18. [CrossRef] [PubMed]

16. Kim, M.H.; Cho, J.S.; Lee, J.H.; Bae, S.Y.; Choi, Y.I.; Park, E.J.; Lee, H.; Ko, J.H. Poplar MYB transcription factor PtrMYB012 and its Arabidopsis AtGAMYB orthologs are differentially repressed by the Arabidopsis miR159 family. Tree Physiol. 2018, 38, 801-812. [CrossRef] [PubMed]

17. Palatnik, J.F.; Wollmann, H.; Schommer, C.; Schwab, R.; Boisbouvier, J.; Rodriguez, R.; Warthmann, N.; Allen, E.; Dezulian, T.; Huson, D.; et al. Sequence and expression differences underlie functional specialization of Arabidopsis microRNAs miR159 and miR319. Dev. Cell 2007, 13, 115-125. [CrossRef]

18. Bologna, N.G.; Mateos, J.L.; Bresso, E.G.; Palatnik, J.F. A loop-to-base processing mechanism underlies the biogenesis of plant microRNAs miR319 and miR159. EMBO J. 2009, 28, 3646-3656. [CrossRef]

19. Li, Y.; Li, C.; Ding, G.; Jin, Y. Evolution of MIR159/319 microRNA genes and their post-transcriptional regulatory link to siRNA pathways. BMC Evol. Biol. 2011, 11, 122. [CrossRef]

20. Aya, K.; Hiwatashi, Y.; Kojima, M.; Sakakibara, H.; Ueguchi-Tanaka, M.; Hasebe, M.; Matsuoka, M. The Gibberellin perception system evolved to regulate a pre-existing GAMYB-mediated system during land plant evolution. Nat. Commun. 2011, 2, 544. [CrossRef]

21. Tsuzuki, M.; Nishihama, R.; Ishizaki, K.; Kurihara, Y.; Matsui, M.; Bowman, J.L.; Kohchi, T.; Hamada, T.; Watanabe, Y. Profiling and characterization of small RNAs in the Liverwort, Marchantia polymorpha, belonging to the first diverged land plants. Plant Cell Physiol. 2016, 57, 359-372. [CrossRef] [PubMed]

22. Lin, S.S.; Bowman, J.L. MicroRNAs in Marchantia polymorpha. New Phytol. 2018, 220, 409-416. [CrossRef] [PubMed]

23. Palatnik, J.F.; Allen, E.; Wu, X.; Schommer, C.; Schwab, R.; Carrington, J.C.; Weigel, D. Control of leaf morphogenesis by microRNAs. Nature 2003, 425, 257-263. [CrossRef] [PubMed]

24. Li, J.; Reichel, M.; Li, Y.; Millar, A.A. The functional scope of plant microRNA-mediated silencing. Trends Plant Sci. 2014, 19, 750-756. [CrossRef] [PubMed]

25. Addo-Quaye, C.; Eshoo, T.W.; Bartel, D.P.; Axtell, M.J. Endogenous siRNA and miRNA targets identified by sequencing of the Arabidopsis degradome. Curr. Biol. 2008, 18, 758-762. [CrossRef] [PubMed]

26. Song, Q.X.; Liu, Y.F.; Hu, X.Y.; Zhang, W.K.; Ma, B.; Chen, S.Y.; Zhang, J.S. Identification of miRNAs and their target genes in developing soybean seeds by deep sequencing. BMC Plant Biol. 2011, 11, 5. [CrossRef] [PubMed] 
27. Liu, N.; Tu, L.; Tang, W.; Gao, W.; Lindsey, K.; Zhang, X. Small RNA and degradome profiling reveals a role for miRNAs and their targets in the developing fibers of Gossypium barbadense. New Phytol. 2015, 206, 352-367.

28. Zhang, J.; Zeng, R.; Chen, J.; Liu, X.; Liao, Q. Identification of conserved microRNAs and their targets from Solanum lycopersicum Mill. Gene 2008, 423, 1-7. [CrossRef]

29. An, F.M.; Chan, M.T. Transcriptome-wide characterization of miRNA-directed and non-miRNA-directed endonucleolytic cleavage using degradome analysis under low ambient temperature in Phalaenopsis aphrodite subsp. formosana. Plant Cell Physiol. 2012, 53, 1737-1750. [CrossRef]

30. Luo, X.; Gao, Z.; Shi, T.; Cheng, Z.; Zhang, Z.; Ni, Z. Identification of miRNAs and their target genes in peach (Prunus persica L.) using high-throughput sequencing and degradome analysis. PLoS ONE 2013, 8, e79090. [CrossRef]

31. Sun, F.; Guo, G.; Du, J.; Guo, W.; Peng, H.; Ni, Z.; Sun, Q.; Yao, Y. Whole-genome discovery of miRNAs and their targets in wheat (Triticum aestivum L.). BMC Plant Biol. 2014, 14, 142. [CrossRef] [PubMed]

32. Li, Y.F.; Zheng, Y.; Addo-Quaye, C.; Zhang, L.; Saini, A.; Jagadeeswaran, G.; Axtell, M.J.; Zhang, W.; Sunkar, R. Transcriptome-wide identification of microRNA targets in rice. Plant J. 2010, 62, 742-759. [CrossRef]

33. Curaba, J.; Spriggs, A.; Taylor, J.; Li, Z.; Helliwell, C. miRNA regulation in the early development of barley seed. BMC Plant Biol. 2012, 12, 120. [CrossRef] [PubMed]

34. Buxdorf, K.; Hendelman, A.; Stav, R.; Lapidot, M.; Ori, N.; Arazi, T. Identification and characterization of a novel miR159 target not related to MYB in tomato. Planta 2010, 232, 1009-1022. [CrossRef] [PubMed]

35. Da Silva, E.M.; Silva, G.F.F.E.; Bidoia, D.B.; da Silva Azevedo, M.; de Jesus, F.A.; Pino, L.E.; Peres, L.E.P.; Carrera, E.; López-Díaz, I.; Nogueira, F.T.S. microRNA159-targeted SlGAMYB transcription factors are required for fruit set in tomato. Plant J. 2017, 92, 95-109. [CrossRef] [PubMed]

36. Wan, L.C.; Zhang, H.; Lu, S.; Zhang, L.; Qiu, Z.; Zhao, Y.; Zeng, Q.Y.; Lin, J. Transcriptome-wide identification and characterization of miRNAs from Pinus densata. BMC Genom. 2012, 13, 132. [CrossRef] [PubMed]

37. Amborella Genome Project. The Amborella genome and the evolution of flowering plants. Science 2013, 342, 1241089. [CrossRef]

38. Li, W.F.; Zhang, S.G.; Han, S.Y.; Wu, T.; Zhang, J.H.; Qi, L.W. Regulation of LaMYB33 by miR159 during maintenance of embryogenic potential and somatic embryo maturation in Larix kaempferi (Lamb.) Carr. Plant Cell Tissue Organ Cult. 2013, 113, 131-136. [CrossRef]

39. Pappas, M.D.C.R.; Pappas, G.J.; Grattapaglia, D. Genome-wide discovery and validation of Eucalyptus small RNAs reveals variable patterns of conservation and diversity across species of Myrtaceae. BMC Genom. 2015, 16, 1113. [CrossRef]

40. Dai, X.; Zhuang, Z.; Zhao, P.X. psRNATarget: A plant small RNA target analysis server (2017 release). Nucleic Acids Res. 2018, 46, W49-W54. [CrossRef]

41. Alonso-Peral, M.M.; Li, J.; Li, Y.; Allen, R.S.; Schnippenkoetter, W.; Ohms, S.; White, R.G.; Millar, A.A. The microRNA159-regulated GAMYB-like genes inhibit growth and promote programmed cell death in Arabidopsis. Plant Physiol. 2010, 154, 757-771. [CrossRef] [PubMed]

42. German, M.A.; Pillay, M.; Jeong, D.H.; Hetawal, A.; Luo, S.; Janardhanan, P.; Kannan, V.; Rymarquis, L.A.; Nobuta, K.; German, R.; et al. Global identification of microRNA-target RNA pairs by parallel analysis of RNA ends. Nat. Biotech. 2008, 26, 941. [CrossRef] [PubMed]

43. Millar, A.A.; Gubler, F. The Arabidopsis GAMYB-like genes, MYB33 and MYB65, are microRNA-regulated genes that redundantly facilitate anther development. Plant Cell 2005, 17, 705-721. [CrossRef] [PubMed]

44. Zheng, Z.; Reichel, M.; Deveson, I.; Wong, G.; Li, J.; Millar, A.A. Target RNA secondary structure is a major determinant of miR159 efficacy. Plant Physiol. 2017, 174, 1764-1778. [CrossRef] [PubMed]

45. Seitz, H. Redefining microRNA targets. Curr. Biol. 2009, 19, 870-873. [CrossRef] [PubMed]

46. Li, Y.; Alonso-Peral, M.; Wong, G.; Wang, M.B.; Millar, A.A. Ubiquitous miR159 repression of MYB33/65 in Arabidopsis rosettes is robust and is not perturbed by a wide range of stresses. BMC Plant Biol. 2016, 16, 179. [CrossRef] [PubMed]

47. Li, J.; Reichel, M.; Millar, A.A. Determinants beyond both complementarity and cleavage govern microR159 efficacy in Arabidopsis. PLoS Genet. 2014, 10, e1004232. [CrossRef] [PubMed]

48. Alonso-Peral, M.M.; Sun, C.; Millar, A.A. MicroRNA159 can act as a switch or tuning microRNA independently of its abundance in Arabidopsis. PLoS ONE 2012, 7, e34751. [CrossRef] [PubMed] 
49. Leydon, A.R.; Beale, K.M.; Woroniecka, K.; Castner, E.; Chen, J.; Horgan, C.; Palanivelu, R.; Johnson, M.A. Three MYB transcription factors control pollen tube differentiation required for sperm release. Curr. Biol. 2013, 23, 1209-1214. [CrossRef] [PubMed]

50. Liang, Y.; Tan, Z.M.; Zhu, L.; Niu, Q.K.; Zhou, J.J.; Li, M.; Chen, L.Q.; Zhang, X.Q.; Ye, D. MYB97, MYB101 and MYB120 function as male factors that control pollen tube-synergid interaction in Arabidopsis thaliana fertilization. PLoS Genet. 2013, 9, e1003933. [CrossRef]

51. Zhao, Y.; Wang, S.; Wu, W.; Li, L.; Jiang, T.; Zheng, B. Clearance of maternal barriers by paternal miR159 to initiate endosperm nuclear division in Arabidopsis. Nat. Commun. 2018, 9, 5011. [CrossRef] [PubMed]

52. Achard, P.; Herr, A.; Baulcombe, D.C.; Harberd, N.P. Modulation of floral development by a gibberellin-regulated microRNA. Development 2004, 131, 3357-3365. [CrossRef] [PubMed]

53. Alves-Junior, L.; Niemeier, S.; Hauenschild, A.; Rehmsmeier, M.; Merkle, T. Comprehensive prediction of novel microRNA targets in Arabidopsis thaliana. Nucleic Acids Res. 2009, 37, 4010-4021. [CrossRef] [PubMed]

54. Pollard, K.S.; Hubisz, M.J.; Rosenbloom, K.R.; Siepel, A. Detection of nonneutral substitution rates on mammalian phylogenies. Genome Res. 2010, 20, 110-121. [CrossRef]

55. Hubisz, M.J.; Pollard, K.S.; Siepel, A. PHAST and RPHAST: Phylogenetic analysis with space/time models. Brief Bioinform. 2011, 12, 41-51. [CrossRef] [PubMed]

56. Crooks, G.; Hon, G.; Chandonia, J.; Brenner, S. WebLogo: A sequence logo generator. Genome Res. 2004, 14, 1188-1190. [CrossRef] [PubMed]

57. Bernhart, S.H.; Hofacker, I.L.; Will, S.; Gruber, A.R.; Stadler, P.F. RNAalifold: Improved consensus structure prediction for RNA alignments. BMC Bioinform. 2008, 9, 1-13. [CrossRef]

58. Todesco, M.; Rubio-Somoza, I.; Paz-Ares, J.; Weigel, D. A collection of target mimics for comprehensive analysis of microRNA function in Arabidopsis thaliana. PLoS Genet. 2010, 6, e1001031. [CrossRef]

59. Rubio-Somoza, I.; Weigel, D. Coordination of flower maturation by a regulatory circuit of three microRNAs. PLoS Genet. 2013, 9, e1003374. [CrossRef]

60. Guo, C.; Xu, Y.; Shi, M.; Lai, Y.; Wu, X.; Wang, H.; Zhu, Z.; Poethig, R.S.; Wu, G. Repression of miR156 by miR159 regulates the timing of the juvenile-to-adult transition in Arabidopsis. Plant Cell 2017, 29, 1293-1304. [CrossRef]

61. Zhao, Y.; Wen, H.; Teotia, S.; Du, Y.; Zhang, J.; Li, J.; Sun, H.; Tang, G.; Peng, T.; Zhao, Q. Suppression of microRNA159 impacts multiple agronomic traits in rice (Oryza sativa L.). BMC Plant Biol. 2017, 17, 215. [CrossRef] [PubMed]

62. Zhang, H.; Zhang, J.; Yan, J.; Gou, F.; Mao, Y.; Tang, G.; Botella, J.R.; Zhu, J.K. Short tandem target mimic rice lines uncover functions of miRNAs in regulating important agronomic traits. Proc. Natl. Acad. Sci. USA 2017, 114, 5277-5282. [CrossRef] [PubMed]

63. Tsuji, H.; Aya, K.; Ueguchi-Tanaka, M.; Shimada, Y.; Nakazono, M.; Watanabe, R.; Nishizawa, N.K.; Gomi, K.; Shimada, A.; Kitano, H.; et al. GAMYB controls different sets of genes and is differentially regulated by microRNA in aleurone cells and anthers. Plant J. 2006, 47, 427-444. [CrossRef] [PubMed]

64. Kaneko, M.; Inukai, Y.; Ueguchi-Tanaka, M.; Itoh, H.; Izawa, T.; Kobayashi, Y.; Hattori, T.; Miyao, A.; Hirochika, H.; Ashikari, M.; et al. Loss-of-function mutations of the rice GAMYB gene impair $\alpha$-amylase expression in aleurone and flower development. Plant Cell 2004, 16, 33-44. [CrossRef] [PubMed]

65. Murray, F.; Kalla, R.; Jacobsen, J.; Gubler, F. A role for HvGAMYB in anther development. Plant J. 2003, 33, 481-491. [CrossRef] [PubMed]

66. Wang, Y.; Sun, F.; Cao, H.; Peng, H.; Ni, Z.; Sun, Q.; Yao, Y. TamiR159 directed wheat TaGAMYB cleavage and its involvement in anther development and heat response. PLoS ONE 2012, 7, e48445. [CrossRef]

67. Li, X.; Bian, H.; Song, D.; Ma, S.; Han, N.; Wang, J.; Zhu, M. Flowering time control in ornamental gloxinia (Sinningia speciosa) by manipulation of miR159 expression. Ann. Bot. 2013, 111, 791-799. [CrossRef]

68. Zhang, Y.; Zhang, X.; Liu, B.; Wang, W.; Liu, X.; Chen, C.; Liu, X.; Yang, S.; Ren, H. A GAMYB homologue CsGAMYB1 regulates sex expression of cucumber via an ethylene-independent pathway. J. Exp. Bot. 2014, 65, 3201-3213. [CrossRef]

69. Vallarino, J.G.; Osorio, S.; Bombarely, A.; Casañal, A.; Cruz-Rus, E.; Sánchez-Sevilla, J.F.; Amaya, I.; Giavalisco, P.; Fernie, A.R.; Botella, M.A.; et al. Central role of FaGAMYB in the transition of the strawberry receptacle from development to ripening. New Phytol. 2015, 208, 482-496. [CrossRef]

70. Plackett, A.R.; Thomas, S.G.; Wilson, Z.A.; Hedden, P. Gibberellin control of stamen development: A fertile field. Trends Plant Sci. 2011, 16, 568-578. [CrossRef] 
71. Aya, K.; Ueguchi-Tanaka, M.; Kondo, M.; Hamada, K.; Yano, K.; Nishimura, M.; Matsuoka, M. Gibberellin modulates anther development in rice via the transcriptional regulation of GAMYB. Plant Cell 2009, 21, 1453-1472. [CrossRef] [PubMed]

72. Liu, B.; De Storme, N.; Geelen, D. Gibberellin induces diploid pollen formation by interfering with meiotic cytokinesis. Plant Physiol. 2017, 173, 338-353. [CrossRef] [PubMed]

73. Gubler, F.; Kalla, R.; Roberts, J.K.; Jacobsen, J.V. Gibberellin-regulated expression of a myb gene in barley aleurone cells: Evidence for Myb transactivation of a high-pI alpha-amylase gene promoter. Plant Cell 1995, 7, 1879-1891. [CrossRef] [PubMed]

74. Gubler, F.; Raventos, D.; Keys, M.; Watts, R.; Mundy, J.; Jacobsen, J.V. Target genes and regulatory domains of the GAMYB transcriptional activator in cereal aleurone. Plant J. 1999, 17, 1-9. [CrossRef] [PubMed]

75. Guo, W.J.; Ho, T.H.D. An abscisic acid-induced protein; HVA22, inhibits gibberellin-mediated programmed cell death in cereal aleurone cells. Plant Physiol. 2008, 147, 1710-1722. [CrossRef] [PubMed]

76. Reichel, M.; Li, Y.; Li, J.; Millar, A.A. Inhibiting plant microRNA activity: Molecular SPONGEs, target MIMICs and STTMs all display variable efficacies against target microRNAs. Plant Biotech. J. 2015, 13, 915-926. [CrossRef] [PubMed]

77. Gong, X.; Bewley, D.J. A GAMYB-like gene in tomato and its expression during seed germination. Planta 2008, 228, 563-572. [CrossRef] [PubMed]

78. Xue, T.; Liu, Z.; Dai, X.; Xiang, F. Primary root growth in Arabidopsis thaliana is inhibited by the miR159 mediated repression of MYB33, MYB65 and MYB101. Plant Sci. 2017, 262, 182-189. [CrossRef]

79. Spanudakis, E.; Jackson, S. The role of microRNAs in the control of flowering time. J. Exp. Bot. 2014, 65, 365-380. [CrossRef]

80. Conti, L. Hormonal control of the floral transition: Can one catch them all? Dev. Biol. 2017, 430, $288-301$. [CrossRef]

81. Gocal, G.F.; Sheldon, C.C.; Gubler, F.; Moritz, T.; Bagnall, D.J.; MacMillan, C.P.; Li, S.F.; Parish, R.W.; Dennis, E.S.; Weigel, D.; et al. GAMYB-like genes, flowering, and gibberellin signaling in Arabidopsis. Plant Physiol. 2001, 127, 1682-1693. [CrossRef] [PubMed]

82. Blazquez, M.A.; Green, R.; Nilsson, O.; Sussman, M.R.; Weigel, D. Gibberellins promote flowering of arabidopsis by activating the LEAFY promoter. Plant Cell 1998, 10, 791-800. [CrossRef]

83. Csukasi, F.; Donaire, L.; Casañal, A.; Martínez-Priego, L.; Botella, M.A.; Medina-Escobar, N.; Llave, C.; Valpuesta, V. Two strawberry miR159 family members display developmental-specific expression patterns in the fruit receptacle and cooperatively regulate Fa-GAMYB. New Phytol. 2012, 195, 47-57. [CrossRef] [PubMed]

84. Wang, C.; Jogaiah, S.; Zhang, W.; Abdelrahman, M.; Fang, J.G. Spatio-temporal expression of miRNA159 family members and their GAMYB target gene during the modulation of gibberellin-induced grapevine parthenocarpy. J. Exp. Bot. 2018, 69, 3639-3650. [CrossRef] [PubMed]

85. Zhang, B. MicroRNA: A new target for improving plant tolerance to abiotic stress. J. Exp. Bot. 2015, 66, 1749-1761. [CrossRef] [PubMed]

86. Liu, H.H.; Tian, X.; Li, Y.J.; Wu, C.A.; Zheng, C.C. Microarray-based analysis of stress-regulated microRNAs in Arabidopsis thaliana. RNA 2008, 14, 836-843. [CrossRef] [PubMed]

87. Reyes, J.L.; Chua, N.H. ABA induction of miR159 controls transcript levels of two MYB factors during Arabidopsis seed germination. Plant J. 2007, 49, 592-606. [CrossRef]

88. Pieczynski, M.; Marczewski, W.; Hennig, J.; Dolata, J.; Bielewicz, D.; Piontek, P.; Wyrzykowska, A.; Krusiewicz, D.; Strzelczyk-Zyta, D.; Konopka-Postupolska, D.; et al. Down-regulation of CBP80 gene expression as a strategy to engineer a drought-tolerant potato. Plant Biotechnol. J. 2013, 11, 459-469. [CrossRef]

89. Zhang, T.; Zhao, Y.L.; Zhao, J.H.; Wang, S.; Jin, Y.; Chen, Z.Q.; Fang, Y.Y.; Hua, C.L.; Ding, S.W.; Guo, H.S. Cotton plants export microRNAs to inhibit virulence gene expression in a fungal pathogen. Nat. Plants 2016, 2, 16153. [CrossRef]

90. Medina, C.; da Rocha, M.; Magliano, M.; Ratpopoulo, A.; Revel, B.; Marteu, N.; Magnone, V.; Lebrigand, K.; Cabrera, J.; Barcala, M.; et al. Characterization of microRNAs from Arabidopsis galls highlights a role for miR159 in the plant response to the root-knot nematode Meloidogyne incognita. New Phytol. 2017, 216, 882-896. [CrossRef]

(C) 2019 by the authors. Licensee MDPI, Basel, Switzerland. This article is an open access article distributed under the terms and conditions of the Creative Commons Attribution (CC BY) license (http://creativecommons.org/licenses/by/4.0/). 